"chillout" rooms with seating and air conditioning to help cooling. For the patient who is taken acutely ill medical management is urgent and includes control of convulsions, measurement of core temperature, rapid rehydration, and possibly the use of dantrolene and active cooling measures.

Some people taking the drug for the first time find the effects disturbing and may complain to their general practitioner of paranoia, hallucinations, insomnia, tachycardia, or muscle stiffness, including trismus or bruxism. In general, all that is needed is reassurance as these acute effects usually resolve within 48 hours. Regular users frequently chew gum to overcome the effects on their jaw muscles; they may present with weight loss, exhaustion, jaundice, "flashbacks," irritability, paranoia, depression, or psychosis. ${ }^{8-14}$

The long term effects of 3,4-methylenedioxymethamphetamine will take time to be documented in detail. At present it seems that repeated use may cause hepatic damage; it is worth mentioning ecstasy when asking about drug habits in young people presenting with unexplained jaundice. ${ }^{5}$ Perhaps the most disturbing aspect of the drug's misuse is the possibility of long term psychiatric effects. Although the drug acts as a neurotoxin at serotoninergic terminals, ${ }^{15}{ }^{16}$ there is no evidence yet that it causes permanent brain damage in man. There have, however, been a few case reports of psychiatric illness ${ }^{10-14}$ but the numbers affected are undoubtedly greater than this'; it could take years until the full toll of psychiatric disorders induced by 3,4-methylenedioxymethamphetamine, including depression and suicide, is established. Claims by misusers and agencies that ecstasy is "safer than alcohol" seem premature. Although the drug does not seem addictive, relaxing the strict legal controls over a drug whose "benefits" are debatable and whose risks are evident would be unwise.

JOHN A HENRY

Consultant Physician,

National Poisons Information Service, $\mid$ Guy's Hospital,

London SE1 9RT

1 Peroutka SJ, Newman $\mathrm{H}$, Harris $\mathrm{H}$. Subjective effects of 3,4-methylenedioxymethamphetamine recreational users. Neuropsychopharmacology 1988:1:273-7.

Greer $G$, Tolbert $R$. Subjective reports of the effects of 3,4-methylenedioxymethamphetamine in clinical setting. 7 Psychoactive Drugs 1986;18:319-27.

3 Gordon CJ, Watkinson WP, O'Callaghan JP, Miller DB. Effects of 3,4 methylenedioxymethamphetamine on autonomic thermoregulatory response of the rat. Pha macol Biochem Behav 1991;38:339-44.

4 Dowling GP. Human deaths and toxic reactions attributed to 3,4-methylenedioxymethamphetamine and MDEA. In: Peroutka SJ, ed. Ecstasy: the clinical, pharmacological, and neurotoxicological effects of the drug 3,4-methylenedioxymethamphetamine. Norwell, Massachusetts: Kluwer, 1990:63-75.

Henry JA, Jeffreys KJ, Dawling S. Toxicity and deaths due to 3,4-methylenedioxymethamphetamine ("ecstasy"). Lancet (in press).

6 Fahal IH, Sallomi DS, Yaqoob M, Williams PS, Bell GM. Ecstasy induced acute renal failure. BMF 1992;305:29.

7 Screaton GR, Singer M, Cairns HS, Thrasher A, Sarner M, Cohen SL. Hyperpyrexia and rhabdomyolysis after 3,4-methylenedioxymethamphetamine ("ecstasy") abuse. Lancet 1991;339:677-8.

Creighton FJ, Black DL, Hyde CE. "Ecstasy" psychosis and flashbacks. $\mathrm{Br} \mathcal{F}$ Psychiatr 1991;159:713-5.

9 Winstock.AR. Chronic paranoid psychosis after misuse of 3,4-methylenedioxymethamphetamine. BMF 1991;302:1150-1.

10 McGuire $P$, Fahy T Chronic paranoid psychosis after misuse of 3,4-methylen dioxymethamphetamine ("ecstasy"). BM7 1991;302:697.

1 Schifano $\mathrm{F}$. Chronic atypical psychosis associated with 3,4-methylenedioxymethamphetamin ("ecstasy") abuse. Lancet 1991;338:1335.

12 Whitaker-Azmitia PM, Aronson TA. "Ecstasy" (3,4-methylenedioxymethamphetamine)-induce panic. Am $\mathcal{F}$ Psychiatry 1989;146:119.

13 Climco RP, Rohrich. H, Sweeney DR, Al-Razi J. Ecstasy-a review of '3, methylenedioxymethamphetamine and MDA. Int $\mathcal{F}$ Psychiatry Med 1987;16:359-71

14 Benazzi F, Mazzoli M. Psychiatric illness associated with "ecstasy." Lancet 1991;338:1520.

15 Ricaurte G, Bryan G, Strauss L, Seiden L, Schuster C. Hallucinogenic amphetamine selectively destroys brain serotonin nerve terminals. Science 1985;229:986-8.

16 McKenna DJ, Peroutka SJ. The neurochemistry and neurotoxicity of 3,4-methylenedioxymethamphetamine "ecstasy, "f Neurochem 1990; 54:14-22.

\title{
Health and safety on the farm
}

\section{Time to raise their status}

Those who idealise rural life in Britain may be surprised to learn that many of our farmworkers face a wider range of hazards than most other workers and that preventive measures lag behind those in most other occupations. Agriculture shares with construction, mining, and fishing the dubious distinction of being a target industry for action in this the European year of safety, hygiene, and health protection at work, ${ }^{1}$ all being among the occupations at highest risk for accidental death and injury.

The agricultural sector averages one fatal injury to a worker every week and one to a member of the public every month. Farmers' health may also be affected by exposure to highly toxic chemicals, organic dusts, zoonotic infections, and a wide range of adverse environmental conditions. ${ }^{2}$ Furthermore, the hazards may extend to farmworkers' families and to visitors, whether or not they are engaged in routine farm work. Concerns also exist about the possible effects of farming practices-for example, the use of pesticides-on the environment and public health. ${ }^{3}$

Our knowledge of the extent of these problems among this scattered and diminishing working population remains sparse. As in the United States, ${ }^{4}$ there is a recognised need for improved surveillance of disease and injury; for more epidemiological investigation of morbidity, including toxicological effects, and mortality; for further study of the associated risk factors; and for devising effective interventions.

If confirmation of these needs was required it has been provided by three papers published in this journal ${ }^{5}$ (p 25) (p 23). ${ }^{7}$ Cameron and Bishop compared the number of adults presenting with farm related injuries to a hospital in rural west Wales with official notifications of serious accidents to the Health and Safety Executive: they found that only a quarter of the major injuries were reported and that official statistics may grossly underestimate overall injury rates. ${ }^{6}$. Unless such accidents are notified intervention by the Agricultural Inspectorate to prevent further mishap is unlikely; most agricultural accidents are related to falls or falling objects, machinery, or livestock - a key factor being the failure to maintain equipment and buildings.

A wider study by the same authors shows how children under 16 account for a disproportionate number of disabling injuries and workplace deaths. ${ }^{7}$ And Croft $e t$ al, by adding further to evidence emerging from other countries suggesting that osteoarthritis should be recognised as an occupational disease in farmers, highlight the importance of lifting and other physical stresses on farms in the causation of degenerative musculoskeletal disease. ${ }^{5}$

Other occupationally related disorders, such as farmer's lung and asthma and zoonotic infections with organisms such as Leptospira hardjo, which is common in dairy workers, ${ }^{8}$ are also unlikely to be recognised because their symptoms are often non-specific. These conditions should be notified by the farm employer or the self employed farmer under the Reporting of Injuries, Diseases and Dangerous Occurrences Regulations (RIDDOR). Even if they come to the farmer's 
notice, however, he or she may fail to report them for the same reasons that accidents go unreported-namely, apathy, fear of litigation, and ignorance of the reporting arrangements. In this, farmers differ little from employers in other industries, and much better systems of surveillance are badly needed throughout British workplaces. ${ }^{9}$ Less awareness and a more fatalistic acceptance of hazards at work are, however, found in farming.

The Health and Safety Executive has been developing special initiatives to counter this, such as producing targeted educational materials and individual health cards, and certain legislative measures, such as the Control of Substances Hazardous to Health (COSHH) Regulations and the recently introduced maximum exposure limited for grain dust, ${ }^{10}$ are expected substantially to increase awareness. Research currently sponsored by the Health and Safety Executive includes projects on grain dust, zoonoses, and sheep dipping (J Wattie, personal communication).

But with the present limited availability of occupational health services in the United Kingdom how can health professionals do more to improve the lot of farmworkers? General practitioners in rural areas continue to be the main point of contact for farmers and their families, yet their training to recognise occupational health problems, including the short term and possible long term effects of exposure to pesticides and other chemicals, is limited. This could be partly rectified by encouraging them to attend the introductory courses in occupational medicine that take place under the auspices of the Faculty of Occupational Medicine. (These could be slanted more to the needs of farmworkers and similar high risk occupational groups such a construction workers. ${ }^{11}$ )

The growing number of NHS hospital consultants in occupational medicine and their increasingly outward looking occupational health services could also provide expert advice on individual patients. In addition, rural practices could undertake health promotion activities targeted at the special needs of farming families.

For occupational health professionals agriculture shows the need to incorporate assessments of environmental impact into their training and practice. This is not only another example of "good earthery" but would represent an important shift in direction for the specialty. Agricultural policies - particularly those that intensify and increase productivity ${ }^{12}-$ may affect occupational and environmental health and safety, and these policies cry out for risk assessment. Two examples are the use of pesticides ${ }^{3}$ and the method of keeping livestock in confined areas, which poses new respiratory hazards to workers ${ }^{2}$ exposed to contaminants of the animal house air and possibly also to the public from these bio-aerosol emissions.

Agribusiness is becoming increasingly capital intensive, with further reductions in the workforce expected from farming reforms initiated by the European Community. These include the requirement that land be set aside out of production, which could disrupt the balance and speed of work and lead to other, less foreseeable consequences. ${ }^{513} \mathrm{How}$ may this legislation affect the risks of accident to workers and to the public enticed to pursue leisure activities on set aside land?

Occupational health doctors will need to work more closely with their colleagues in public health medicine to achieve these innovatory advances in prevention. If doctors want to exert greater influence over industry and the government on matters of occupational and environmental health then agriculture is a good place to start. ${ }^{14}$

PETER J BAXTER

Consultant Occupational Physician,

Department of Community Medicine,

University of Cambridge Clinical School,

Addenbrooke's Hospital,

Cambridge CB2 2QQ

1 Johns M. European year of health and safety. Toxic Substances Bulletin 1992;18:1-2

2 May JJ. Issues in agricultural health and safety. Am $\mathcal{F}$ Ind Med 1990;18:121-31.

3 The BMA guide to pesticides, chemicals and health. London: Edward Arnold, 1992.

Centers for Disease Control. Surgeon general's conference on agricultural safety and health, 1991. MMWR 1992;41:5-12.

Croft P, Coggon D, Cruddas $M$, Cooper C. Osteoarthritis of the hip: an occupational disease in farmers. BMF 1992;304:1269-72.

6 Cameron D, Bishop C. Farm accidents in adults. BMJ 1992;305:25-6.

7 Cameron D, Bishop C, Sibert JR. Farm accidents in children. BMF 1992;305:23-5.

Watkins SA. Leptospirosis as an occupational disease. Brf Ind Med 1986;43:721-5.

Carter JT. There's a lot of it about? $\mathrm{Br} f$ Ind Med 1991;48:289-91.

10 Health and Safety Executive. Occupational exposure limits 1992. London: HMSO, 1992 (EH490/92).

11 Snashell D. Safety and health in the construction industry. BMF 1990;301:563-4

12 Donham KJ. Prologue: agricultural occupational and environmental health: policy strategies for the future. Am F Ind Med 1990;18:107-19.

13 Richardson D. A harvest of sorrows. Financial Times May 23/24:7.

14 Delamothe T. Airs, waters, places, and doctors. BMF 1992;304:268.

\section{Trauma, back pain, malingering, and compensation}

\section{No dependable spine "lie detectors" yet}

The dawn of the railway age was associated with frequent railway accidents, and many passengers suffered injuries to their spines and developed chronic back pain. "Railway spine" was often the subject of litigation. Debate raged about whether this was "concussion of the spine", 1 minor organic brain damage, ${ }^{2}$ hysteria, or deliberate malingering associated with the prospects of compensation. ${ }^{3}$ Similar arguments are made today in medicolegal claims for back pain.

Commonly a patient has had an accident, most often at work or in a car, and has developed back pain, perhaps referred into the lower limb. Most acute episodes of back pain resolve over a few days or weeks, but some people despite extensive treatment (which may include surgery) develop persistent and widespread symptoms and become severely disabled. The problems seem grossly disproportionate to objective evidence of damage in the spine, even that obtained with the most sophisticated investigations, including mag- netic resonance imaging and computed tomography. A legal claim is made, which drags on for several years. Although agreement is reached about who was at fault in the accident, the argument continues about the severity of the injury and whether the patient is really suffering pain and is disabled.

Henry Miller introduced the term "accident neurosis" to describe a series of patients with psychoneurotic complaints after trauma. ${ }^{4} \mathrm{He}$ suggested that the process of seeking compensation plays an important part in the chronicity of the symptoms. A comparison of two groups of patients with similar degrees of back injury - one group seeking compensation and the other for whom no compensation was availablesupports this. It found that the severity of pain, disability, and psychological disturbance and the duration of unemployment and time off work were significantly greater in the group seeking compensation. ${ }^{5}$

The compensation process itself, with its prolonged series 